\title{
The Implementation of Speed Control on IPMSM using Simple Nonlinear Adaptive Back-Stepping
}

\author{
JeonYong-Ho and ShinWon Lee ${ }^{1}$ \\ Jungwon University, \\ Goesan-eup, Goesan-gun, Chungbuk, 367-805, Republic of Korea \\ waterjliar@jwu.ac.kr,swlee@jwu.ac.kr
}

\begin{abstract}
In this paper, we propose a design method of nonlinear adaptive back-stepping controller. Many back-stepping controllers design that assume to control with the d-axis current O[A], but the suggested controller design that is possible to control the place on that the d-axis current is not O[A]. The d-axis current increases additional terms. This controller used an approximated term with not spoil the reliability of system to overcome the shortcomings. The proposed controller is tested through experiment with a 1-hp IPMSM, and is designed to have asymptotically stability and to take a precise tracking performance for different speed, and is robust to adapt real time on load change.
\end{abstract}

Keywords: IPMSM, Interior Permanent magnet Synchronous Motor, Nonlinear, Adaptive, Back-stepping control

\section{Introduction}

Recently, it is increased to use of AC motors than the DC motors. The DC motors require regular maintenance by mechanical contact of brush and commutator. But AC motors can use semi-permanent by the use of the electronic commutator. In addition, the complex control structure of AC motors is simplified and generalized due to the development of vector control, and were available accurate servo motor control.

Synchronous Motor is divided into IPMSM and SPMSM. IPMSM (Interior Permanent Magnet Synchronous Motor) inserts permanent magnet into rotor and SPMSM (Surface mounted Permanent Magnet Synchronous Motor) attaches permanent magnet to surface. IPMSM exist the differences of reluctance between $\mathrm{d}$-axis and q-axis and reluctance torque to occur due to differences of reluctance between d-axis and q-axis. In the flux weakening operation, this increases output torque of motor and controls stator current, and adjusts gap flux. It is used to extend the speed range of operation.

Commonly used in the control of motor, these linear controllers such as $\mathrm{P}$ (Proportion), I (Integral), and D (Differential) has a good performance of the controller. However, to obtain more precise control and a good response, the controller of adaptable structure in real-time is required for the variation of load torque and parameter. The nonlinear adaptive back-stepping controller has a number of advantages to control the nonlinear system. This controller can configure the controller that adds to the control input a term or damping term for the linearization of nonlinear system and obtains asymptotic stability of the system, and adapts to the effect of parameter

${ }^{1}$ Corresponding author 
variation of the system. But, it should process a complicated procedure to design stepby-step according to the integral. The operation of the formula has too many.

[1-2] were presented the design method of the SPMSM (Surface Mounted Permanent Magnet Synchronous Motor) didn't exist difference of magnetic resistance between daxis and q-axis. [3-7] were designed the method of the IPMSM that assumes the current of d-axis is $0[\mathrm{~A}]$. This method can reduce the computation of the formula, but, it does not apply to the control on MTPA (Maximum Torque per Ampere) or Flux-Weakening Operation requiring d-axis current. The reference [8] was designed the controller has the presence of both the d-q axis current, but has disadvantage of a lot computational complexity of the formula.

This paper proposed the design method that can be configured robust and simply nonlinear adaptive back-stepping controller for precise speed control of IPMSM. Section 2 to section 4 describes the design method of proposed controller. Section 5 is derived the adaptive law to change in load variation. Section 6 is verified the speed control performance and adaptive performance of the variation of load torque through simulation on the designed controller.

\section{IPMSM Motor Model}

The assumption is the reluctance of motor is not saturation, ignores core loss, and occurs sinusoidal of back electromotive force, the following equation (1) to (4) express mathematical model.

$$
\begin{aligned}
& \dot{\omega}_{r}=\frac{1}{J_{m}}\left(-B_{m} \omega_{r}+\tau_{e}-\tau_{l}\right) \\
& \dot{i}_{d}=\frac{1}{L_{d}}\left(-R_{s} i_{d}+p L_{q} \omega_{r} i_{q}+V_{d}\right) \\
& \dot{i}_{q}=\frac{1}{L_{q}}\left(-R_{s} i_{q}-p L_{d} \omega_{r} i_{d}-p \varphi_{f} \omega_{r}+V_{q}\right) \\
& \tau_{e}=\frac{3}{2} p\left(\varphi_{f} i_{q}+\left(L_{d}-L_{q}\right) i_{d} i_{q}\right)
\end{aligned}
$$

$V_{d}, V_{q}$ are input voltage of $\mathrm{d}$-axis and q-axis respectively, $i_{d}, i_{q}$ are current of d-axis and q-axis respectively, $\omega_{r}$ is mechanical velocity of rotor, $\tau_{e}$ is the torque caused by electromagnetic, $\tau_{l}$ is load torque, $R_{s}$ is phase resistance of stator, $L_{d}, L_{q}$ are inductance of $\mathrm{d}$-axis and q-axis respectively, $\varphi_{f}$ is flux of rotor permanent magnet, $p$ is pole pair of permanent magnet, $J_{m}$ is moment of inertia of motor rotor, and $B_{m}$ is viscous friction coefficient of motor rotor.

\section{Design of Reference Angular Velocity}

This paper is assumed the mechanical parameters and electrical parameters are known for the controller design of motor. When tracking reference angular velocity for velocity controller design is $\omega_{\text {ref }}$, angular error is the following equation (5). 


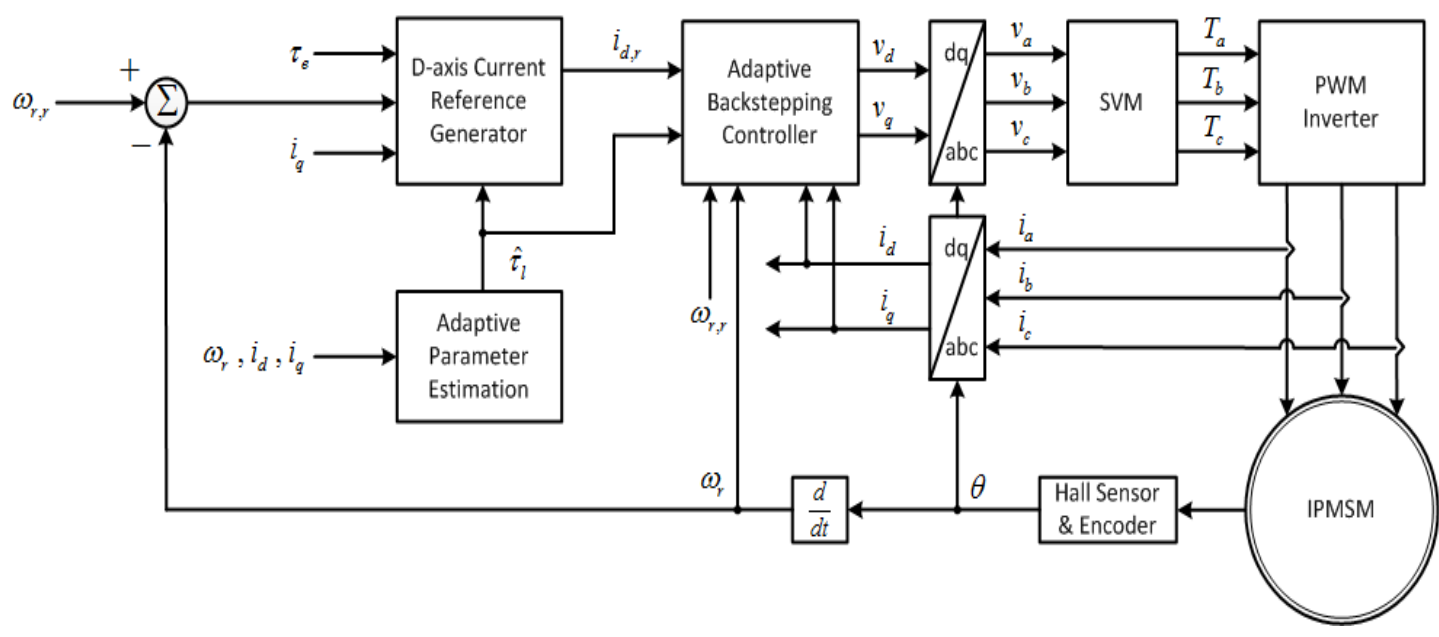

Figure 1. The block diagram of adaptive back-stepping controller

$$
e_{\omega}=\omega_{r e f}-\omega_{r}
$$

Lyapunov function for the velocity tracking is the following equation (5).

$$
V_{1}=\frac{1}{2} e_{\omega}^{2}
$$

$\alpha\left(\tau_{e}\right)$ is the virtual control input to stabilize Lyapunov function of equation (6), when condition is $\dot{V}_{1}<0, \alpha\left(\tau_{e}\right)$ is the following equation (7).

$$
\alpha\left(\tau_{e}\right)=B_{m} \omega_{r}+\tau_{l}+J_{m} \dot{\omega}_{r e f}+J_{m} k_{\omega} e_{\omega}
$$

To design possible measure current, this paper uses equation (4) and calculates electrical output torque.

When synchronized $\mathrm{d}$-axis reference current for rotor is $i_{d, r}$ and $\mathrm{q}$-axis reference current is $i_{q, r}$, the error of current is equation (8), (9) respectively.

$$
\begin{gathered}
e_{d}=i_{d, r}-i_{d} \\
e_{q}=i_{q, r}-i_{q}
\end{gathered}
$$

The equation (10) is the electrical reference output torque that consisted of reference current.

$$
\alpha\left(\tau_{e}\right)=\frac{3}{2} p\left(\varphi_{f} i_{q, r}+\left(L_{d}-L_{q}\right) i_{d, r} i_{q, r}\right)
$$

\section{Design of Current Controller}

IPMSM exist the reluctance torque that occurs due to differences of magnetic resistance between $\mathrm{d}$-axis and q-axis. It can increase the output torque of motor. In addition, it has advantage to extend the range of operation speed through adjusting gap flux using stator current. It should be possible to control for increasing output of torque 
and expanding driving range when d-axis current is not $0[\mathrm{~A}]$. When $i_{d, r}$ is not $0[\mathrm{~A}]$ and constant, $i_{q, r}$ is the following equation (12).

$$
\begin{aligned}
i_{d, r} & =\text { constant } \\
i_{q, r} & =\frac{2}{3 p} \frac{B_{m} \omega_{r}+\tau_{l}+J_{m} \dot{\omega}_{r e f}+J_{m} k_{\omega} e_{\omega}}{\varphi_{f}+\left(L_{d}-L_{q}\right) i_{d, r}}
\end{aligned}
$$

The equation (12) is equal to equation (7) and (10) and organized by $i_{d, r}$. The Lyapunov function for design of current controller using equation (11) and (12) is the following equation (13).

$$
V_{2}=\frac{1}{2} e_{\omega}^{2}+\frac{1}{2} e_{d}^{2}+\frac{1}{2} e_{q}^{2}
$$

To evaluate the asymptotic stability of equation (13), the time variation of equation (13) is $\dot{V}_{2}<0$. The time variation of $V_{2}$ is the equation (14).

$$
\dot{V}_{2}=\dot{e}_{\omega} e_{\omega}+\dot{e}_{d} e_{d}+\dot{e}_{q} e_{q}
$$

The time variation of error equation of equation (14) is the equation (15) to (17).

$$
\begin{aligned}
& \dot{e}_{\omega}=\dot{\omega}_{r e f}-\dot{\omega}_{r} \cong-k_{\omega} e_{\omega} \\
& \dot{e}_{d}=\dot{i}_{d, r}-\dot{i}_{d}=\dot{i}_{d, r}-\left(-\frac{R_{s}}{L_{d}} i_{d}+\frac{p L_{q} \omega_{r}}{L_{d}} i_{q}+\frac{1}{L_{d}} V_{d}\right) \\
& \dot{e}_{q}=\dot{i}_{q r}-\dot{i}_{q}=\dot{i}_{q r}-\left(-\frac{R_{s}}{L_{q}} i_{q}-\frac{p L_{d}}{L_{q}} \omega_{r} i_{d}-\frac{p \varphi_{f}}{L_{q}} \omega_{r}+\frac{1}{L_{q}} V_{q}\right)
\end{aligned}
$$

The equation (15) is obtained by substituting equation (7) and (12) with equation (1). $k_{\omega}$ is gain for compensating speed error. The equation (16) obtains using equation (2) and (11) and the equation (17) obtains equation (3) and (12).

When the condition of equation (14) is $\dot{V}_{2}<0$, the design of control input for current controller is the following equation (18) to (19).

$$
\begin{aligned}
& V_{d}=R_{s} i_{d}-p L_{q} \omega_{r} i_{q}+L_{d} \dot{i}_{d, r}+L_{d} k_{d} e_{d} \\
& V_{q}=R_{s} i_{q}+p L_{d} \omega_{r} i_{d}+p \varphi_{f} \omega_{r}+L_{q} i_{q, r}+L_{q} k_{q} e_{q}
\end{aligned}
$$

$k_{d}, k_{q}$ are gain for compensating error of current controller, the condition is $\dot{V}_{2}<0$.

When the proper amount of gain $k_{\omega}, k_{d}$, and $k_{q}$ set to be $\dot{V}_{2}<0$, we can configure the controller with the equation (18) and (19) that is made speed tracking and asymptotic stable motor system. 


\section{Controller Design Including Adaptation Law of Load Torque}

The controller designed from Section 3 to Section 4 has occurred parameter variation due to external environment, and didn't guarantee the stable operation. Among them, the most severe parameter is the load torque that affects a q-axis reference current of equation (12). The following equation (20) defines the error of load torque to induce estimation of load torque.

$$
\tilde{\tau}_{l}=\hat{\tau}_{l}-\tau_{l}
$$

$\hat{\tau}_{l}$ is point estimate of load torque, $\tilde{\tau}_{l}$ is the difference between the estimate and the actual value.

The equation (21) is a Lyapunov function for stable controller including error of load torque defined as equation (20).

$$
V=\frac{1}{2} e_{\omega}^{2}+\frac{1}{2} e_{d}^{2}+\frac{1}{2} e_{q}^{2}+\frac{1}{2 \gamma} \tilde{\tau}_{l}^{2}
$$

$\mathrm{Y}$ is the adaptation gain and has positive value. The equation (22) is the variation rate of time in the equation (21).

$$
\dot{V}=\dot{e}_{\omega} e_{\omega}+\dot{e}_{d} e_{d}+\dot{e}_{q} e_{q}+\frac{1}{\gamma} \tilde{\tau}_{l} \dot{\tau}_{l}
$$

The equation (23) reconfigures $i_{q, r}$ of the equation (12) with estimate of load torque to design the value of equation (22) is negative.

$$
\hat{i}_{q, r}=\frac{2}{3 p} \frac{B_{m} \omega_{r}+\hat{\tau}_{l}+J_{m} \dot{\omega}_{r e f}+J_{m} k_{\omega} e_{\omega}}{\varphi_{f}+\left(L_{d}-L_{q}\right) i_{d, r}}
$$

The equation (15) to equation (17) is modified as equation (24) to (25) using equation (23).

$$
\begin{aligned}
\dot{e}_{\omega} & =-k_{\omega} e_{\omega}-\frac{1}{J_{m}} \tilde{\tau}_{l} \\
\dot{e}_{q} & =\dot{\hat{i}}_{q r}-\dot{i}_{q} \\
& =\dot{\hat{i}}_{q r}-\left(-\frac{R_{s}}{L_{q}} i_{q}-\frac{p L_{d}}{L_{q}} \omega_{r} i_{d}-\frac{p \varphi_{f}}{L_{q}} \omega_{r}+\frac{1}{L_{q}} V_{q}\right)
\end{aligned}
$$

After the equation (22) substitute into the equation (24) to (25) and (16), the current controller of q-axis is designed as the following equation (26).

$$
V_{q}=R_{s} i_{q}+p L_{d} \omega_{r} i_{d}+p \varphi_{f} \omega_{r}+L_{q} \dot{\hat{i}}_{d, r}+L_{q} k_{q} e_{q}
$$

When d-axis control input uses equation (18) and q-axis control input uses equation (26), the equation (22) is summarized as equation (27).

$$
\dot{V}=-k_{\omega} e_{\omega}^{2}-k_{d} e_{d}^{2}-k_{q} e_{q}^{2}-\frac{1}{J_{m}} \tilde{\tau}_{l} e_{\omega}+\frac{1}{\gamma} \tilde{\tau}_{l} \dot{\tilde{\tau}}_{l}
$$


When the right amount of gain in equation (27) $k_{d}, k_{q}$, and $k_{\omega}$ set up and the rest of the term except the square of error is 0 , the equation (27) can be negative. Thus, the evaluation function is asymptotic stable at the origin. When using this law, the adaptation law of load torque is the following equation (28).

$$
\dot{\hat{\tau}}_{l}=\gamma \frac{e_{\omega}}{J_{m}}
$$

$\dot{\hat{\tau}}_{l}$ in equation (28) is the same that equation (20) differentiate for the time. When the equation (28) is used in adaptation law of load torque and control input of the equation (18) and (26), the equation (22) is shown negative semi-definite.

\section{Experiment Result}

The parameters of motor that used in the actual experiment are shown in Table 1. The part of controller that is the core edits the program using DLL supported function of simulation to verify in simulation, and it was applied to the DSP board that is used in the actual experiment. By doing so, it reduced the error that occurs between the simulation and experiment.

Table 1. IPMSM parameter

\begin{tabular}{l|l}
\hline Motor Rated Power & 3-phase 1hp \\
\hline Motor Rated Speed & $1200 \mathrm{RPM}$ \\
\hline Pole Pair Number $\quad p$ & 2 \\
\hline Stator Resistance, $\quad R_{s}$ & $0.048 \Omega$ \\
\hline D-axis Inductance, $L_{d}$ & $0.42 \mathrm{mH}$ \\
\hline Q-axis Inductance, $L_{q}$ & $1.2 \mathrm{mH}$ \\
\hline Moment of Inertia, $J_{m}$ & $0.002 \mathrm{Kgm}{ }^{2}$ \\
\hline Friction coefficient, $B_{m}$ & $0.01 \mathrm{Nm} / \mathrm{rad} / \mathrm{s}$ \\
\hline Magnetic Flux Constant, $\varphi_{f}$ & $0.04135 \mathrm{volt} / \mathrm{rad} / \mathrm{s}$ \\
\hline
\end{tabular}

At this time, the current gain of back-stepping controller is $k_{d}=k_{q}=10000$ and the velocity gain is $k_{\omega}=10$. And the adaptive gain to estimate load variation is $\gamma=0.0002$.

The reason that operating frequency of the adaptive back-stepping controller can't do quickly was to use the increment encoder of high performance with 4000 [pulse] per 1 cycle but the resolution is 150 [RPM/Pulse] when the angular velocity of the motor is measured per $10[\mathrm{Khz}]$ on $1200[\mathrm{RPM}]$. When the measurement of speed performs on fast cycle, the angular velocity control output can become unstable due to increase angular resolution. To measure fast and precise speed, it needs to use resolver or high precision encoder, or apply the mathematical model observer. For this reason, in this 
experiment, the operating frequency of the adaptive back-stepping controller set $500[\mathrm{~Hz}]$. The actual interval variables that can't be measured used the DAC (Digital to Analog Converter) that is possible to compare with the actual value.

In the Figure 2 to Figure 4, the velocity reference set $20[\mathrm{rad} / \mathrm{s}], 60[\mathrm{rad} / \mathrm{s}]$, and 120 $[\mathrm{rad} / \mathrm{s}]$ respectively, and load torque is constant at $0.5[\mathrm{Nm}]$.

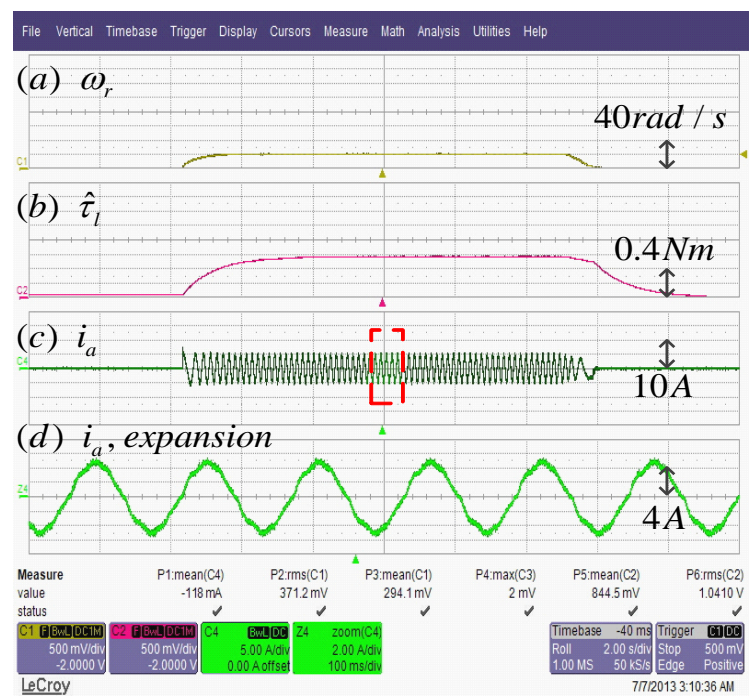

Figure 2. Experiment results of IPMSM $(20 \mathrm{rad} / \mathrm{s}, 0.5 \mathrm{Nm})$

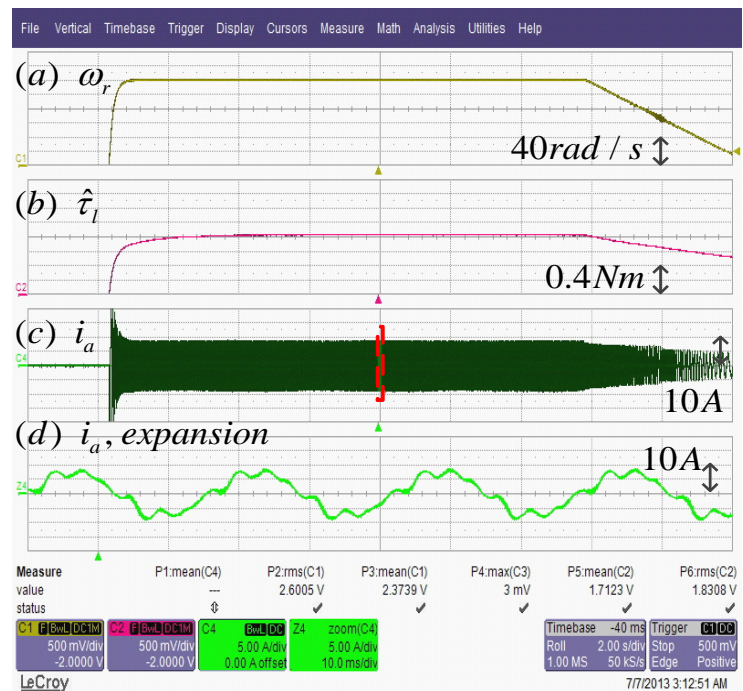

Figure 3. Experiment results of IPMSM (60rad/s, $0.5 \mathrm{Nm})$ 


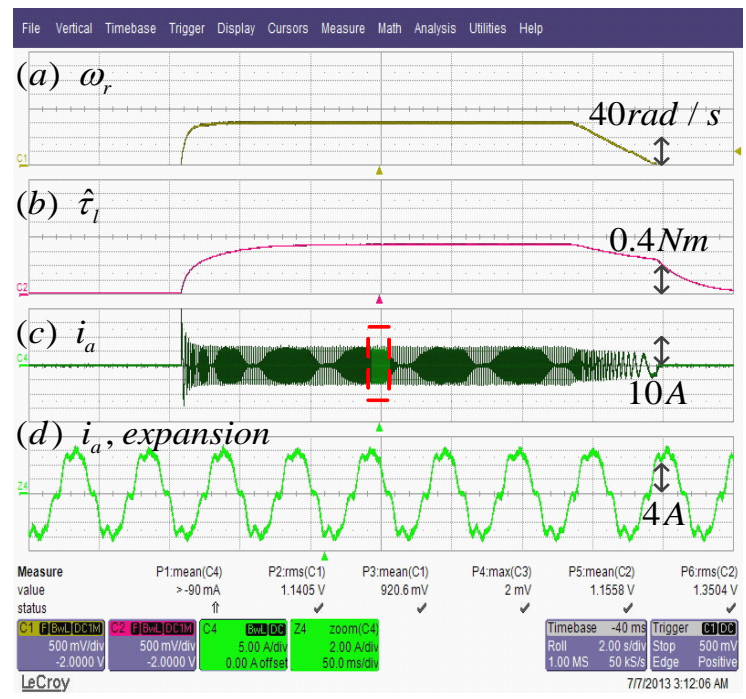

\section{Figure 4. Experiment results of IPMSM (120rad/s, $0.5 \mathrm{Nm})$}

In Figure 2 to Figure 4, (a) is the angular velocity of the motor, (b) is the estimator of the load torque, (c) is the value of the a-phase current, and (d) is enlarged to a-phase current. The estimation of the load torque is on high depending on the speed, is due to rising friction on the speed. The speed tracking is being made in $1.5[\mathrm{~s}]$, the steady state error converges within 1[\%]. The estimator of load torque is addition of actual load $0.5[\mathrm{Nm}]$ and the coefficient of friction multiplied by the angular velocity, and the load torque estimates about $0.6[\mathrm{Nm}]$ at $20[\mathrm{rad} / \mathrm{s}]$, about $0.7[\mathrm{Nm}]$ at $60[\mathrm{rad} / \mathrm{s}]$, and about $0.8[\mathrm{Nm}]$ at $120[\mathrm{rad} / \mathrm{s}]$ respectively. In the result of Figure 2 to Figure 4 , it can be seen that the designed controller estimates exactly the load and speed in general speed scope of the motor.

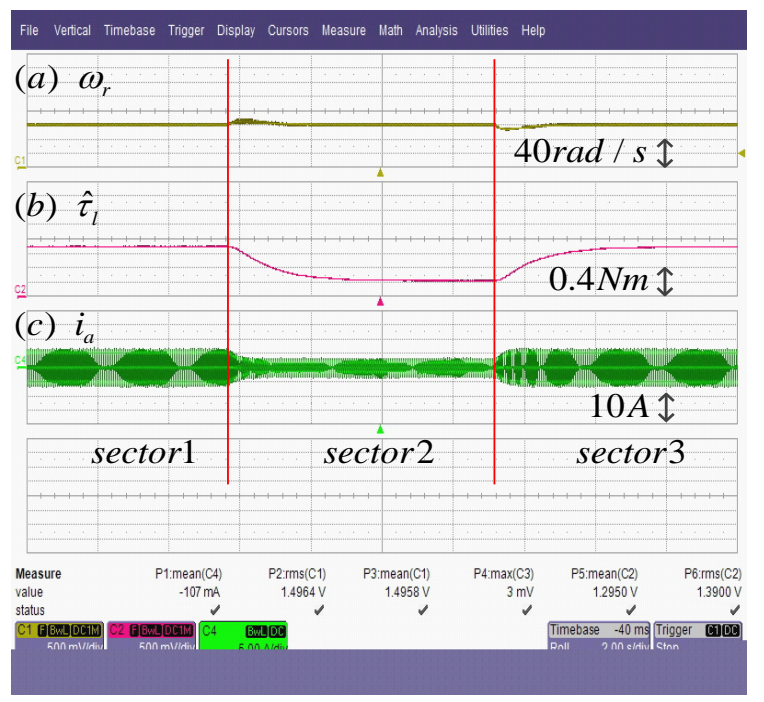

Figure 5. Experiment results of load torque change (60rad/s)

Figure 5 is the result that load torque changed at $0.7[\mathrm{Nm}]$ to $0.2[\mathrm{Nm}]$. The load torque was applied $0.7[\mathrm{Nm}]$ for section 1 and section 3 , and $0.2[\mathrm{Nm}]$ for Section 2 
respectively. When the load torque changes, the tracking value of speed is the variation of about 5[\%] and the steady state reaches within $1[\mathrm{~s}]$. The stability of the designed controller was verified that the tracking time of load torque is same as the previous experiments result and the variation of speed doesn't appear significantly at the variation of load torque.

\section{Conclusion}

This paper is proposed the method that can be simplified to design the nonlinear adaptive back-stepping controller for the speed tracking of IPMSM.

First, in the angular velocity controller, the back-stepping controller design is simplified to ignore real torque input, the based value of torque, and the error. The current controller is designed to separate $\mathrm{d}-\mathrm{q}$ axis current coupled to each other when $\mathrm{d}$ axis current is constant. And we proved the designed controller without error is asymptotic stability of the entire system through setting proper control gain. Through simulations and experiments, the controller is showed the stable speed tracking, in particular, the proposed controller is verified stable despite variation of load in the experiment.

\section{Acknowledgements}

This article is a revised and expanded version of a paper entitled [A Simple Nonlinear Adaptive Back-Stepping Speed Control of IPMSM] presented at International Symposium on Advanced and Applied Convergence held on November 14-16, 2013 at Seoul, Korea.

\section{Reference}

[1] J. Zhou and Y. Wang, "Adaptive back-stepping speed controller design for a permanent magnet synchronous motor", Electric Power Applications, IEEE, Proceedings, vol. 149, no. 2, (2002).

[2] L. Dongliang and Z. Lixin, "Application of back-stepping control in PMSM servo system", Electronic Measurement \& Instruments, vol. 3, (2009), pp. 638-641.

[3] M. Ouassaid, M. Cherkaoui and Y. Zidani, "A Nonlinear Speed Control for a PM Synchronous Motor Using an Adaptive Back-stepping Control Approach", 2004 IEEE, International Conference on Industrial Technology, vol. 3, (2004), pp. 1287-1292.

[4] S. Rebouh, A. Kaddouri, R. Abdessemed and A. Haddoun, "Adaptive Back-stepping speed Control for a Permanent Magnet Synchronous Motor”, Management and Service Science, International Conference, (2011), pp. 1-4.

[5] L. Yuan, F.Y. He and W. Feng, "Nominal Model-Based Control for Permanent Magnet Synchronous Motor", International Conference on Intelligent Human-Machine Systems and Cybernetics, vol. 2, (2009), pp. 343346.

[6] W. Limei, S. Jia and Z. Xin, "Nonlinear Back-stepping Design of IPMSM Controller", Proceeding of International Conference on Electric -al Machines and Systems, (2007), pp. 642-644.

[7] D. Liu, W. Yan and Y. He, "Speed Tracking Control of PMSM with Adaptive Back -stepping", Proceedings of the 6th World Congress on Intelligent Control and Automation, (2006), pp.1986-1989.

[8] J.-T. Yu, C.-K. Lin, L.-C. Fu and T.-H.Liu, "Adaptive Back-stepping Servo Control for IPMSM Drive Systems with MTPA - An Implicit and Symbolic Computation Approach", SICE Annual Conference, (2010), pp. 121-126.

[9] Y. Jeon and S. Lee, "A Simple Nonlinear Adaptive Back-Stepping Speed Control of IPMSM", ISAAC, (2013), pp. 305-308. 
International Journal of Control and Automation Vol.7, No.5 (2014) 